\title{
Decision on folic acid fortification in Europe must consider both risks and benefits
}

\author{
A David Smith professor emeritus ${ }^{1}$, Helga Refsum professor of nutrition ${ }^{2}$, Jacob Selhub senior \\ scientist and professor ${ }^{3}$, Irwin H Rosenberg senior scientist and university professor ${ }^{4}$
}

${ }^{1}$ Department of Pharmacology, University of Oxford, Oxford, UK; ${ }^{2}$ Department of Nutrition, Institute of Basic Medical Sciences, University of Oslo, Oslo, Norway; ${ }^{3}$ Jean Mayer USDA Human Nutrition Research Center on Aging, Tufts University, Boston, MA 02111, USA; ${ }^{4}$ Friedman School of Nutrition Science and Policy, Tufts University, Boston, MA, USA

We are worried by the following statement in a recent editorial on the safety of folic acid fortification: "No important adverse effects have been identified to date, probably because a modest level of fortification has proved very effective in preventing these devastating birth defects." It is unusual in medicine to claim that a treatment is safe just because it is effective in treating or preventing one condition-objective evidence is needed on overall safety and the side effect profile in all people exposed to the "treatment," not only those who benefit. It seems that WHO also has not fully assessed the possible harmful effects of folic acid because its guideline on folate and neural tube defects (NTDs) states: "high folic acid intake has not reliably been shown to be associated with negative health effects."

The editorial's claim that half of all NTDs could be prevented by mandatory fortification in Europe is misleading, because the effectiveness of fortification depends on the baseline prevalence of NTDs, with a smaller reduction in countries with low prevalence. $^{3}$ The accompanying report found a prevalence of NTDs in Europe of 9.1 per 10000 births. ${ }^{4}$ In eight US states the prevalence was 10.7 before fortification but fell to 7.0 after fortification. ${ }^{5}$ It is not likely that, if fortification is introduced, the prevalence in Europe will drop to much below 7.0 per 10 000 because only a certain proportion of NTDs are caused by low folate status and a floor effect has been noticed. ${ }^{3}$

Regarding possible adverse effects, for each NTD prevented, mandatory fortification of flour products with folic acid will expose several hundred thousand Europeans to folic acid, a synthetic form of folate not widely found in nature. ${ }^{6}$ Increasing evidence suggests that certain subgroups of the population may be harmed by exposure to high levels of folic acid. ${ }^{6}$ Some of the most consistent evidence relates to older people. In Chicago, older people who consumed $>349 \mu \mathrm{g}$ total folate per day (half of which came from supplements) had a faster rate of cognitive decline over six years than those who consumed $<221 \mu \mathrm{g}$ folate per day. ${ }^{7}$ Furthermore, those who took daily supplements containing $>400 \mu \mathrm{g}$ folic acid showed significant cognitive decline compared with non-supplement users. ${ }^{7}$ Another study found that after mandatory fortification in the US, those with poor vitamin $B_{12}$ status but high serum folate $(>59 \mathrm{nmol} / \mathrm{L})$ had an increased risk of anaemia or cognitive impairment (or both), ${ }^{8}$ which seemed to be related to the presence of unmetabolised folic acid in the circulation. ${ }^{9}$ A similar cognitive effect was found in Australia: older people with high red blood cell folate $(1594 \mathrm{nmol} / \mathrm{L})$ and low vitamin $\mathrm{B}_{12}$ status $(<250 \mathrm{pmol} / \mathrm{L})$ showed an increased risk of cognitive impairment. ${ }^{10}$ In this study, even those with low-normal $\mathrm{B}_{12}$ (median $383 \mathrm{pmol} / \mathrm{L}$ ) but high red blood cell folate had an increased risk of impairment. In surveys across Europe, typically $6-10 \%$ of those aged $\geq 60$ years are vitamin $B_{12}$ deficient (plasma vitamin $B_{12}<150 \mathrm{pmol} / \mathrm{L}$ ) and the prevalence of deficiency increases with age. Furthermore, another $20-30 \%$ have marginal status (vitamin $B_{12}$ 148-221 $\mathrm{pmol} / \mathrm{L}) .{ }^{1-14}$ Thus a considerable proportion of older people in Europe would be at risk of cognitive impairment if exposed to high folate levels.

The editorial says that the literature on folic acid and cancer is inconsistent. ${ }^{1}$ However, a meta-analysis of almost 50000 people in folic acid trials found a $6 \%$ increased risk of cancer in those taking folic acid, although this risk was not quite significant (relative risk $1.06,95 \%$ confidence interval 0.99 to 1.13$).{ }^{15} \mathrm{We}$ do not know whether this meta-analysis was sufficiently powered to show a significant association of $6 \%$, which is a relevant increase in cancer risk given its high prevalence. A second problem is that several relevant subgroups were not examined. In the Norwegian trials, patients who took folic acid who also had the 677TT genotype of the MTHFR gene had a greater risk of dying from cancer than those with the CC genotype. ${ }^{16}$ An observational study also reported that women with the 677TT genotype and high serum folate had a higher risk of breast cancer than those with lower folate. ${ }^{17}$ Another 
example of the importance of subgroups is that people with different genotypes of the $19 \mathrm{bpdel}$ polymorphism in the DHFR gene show different associations between folate and cancer and also between folate and cognition. ${ }^{18}$

Although high blood levels of folate may partly be caused by the consumption of fortified breakfast cereals or folate supplements, mandatory fortification in the US undoubtedly increased the prevalence of high serum levels. ${ }^{19}$ A similar effect is likely in Europe if fortification is introduced. In view of the evidence that high folate levels may not be harmless, European authorities should carefully consider all the evidence on risks and benefits before recommending mandatory folic acid fortification.

\section{Competing interests: None declared.}

1 Mills JL, Dimopoulos A. Folic acid fortification for Europe? BMJ 2015;351:h6198

2 WHO. Optimal serum and red blood cell folate concentrations in women of reproductive age for prevention of neural tube defects. Guideline. Secondary Optimal serum and red blood cell folate concentrations in women of reproductive age for prevention of neural tube defects. 2015

3 Heseker HB, Mason JB, Selhub J, et al. Not all cases of neural-tube defect can be prevented by increasing the intake of folic acid. Br J Nutr 2009;102:173-80.

Khoshnood B, Loane $\mathrm{M}$, Walle $\mathrm{H}$, et al. Long term trends in prevalence of neural tube defects in Europe: population based study. BMJ 2015;351:h5949.

5 Williams J, Mai CT, Mulinare J, et al. Updated estimates of neural tube defects prevented by mandatory folic acid fortification-United States, 1995-2011. MMWR Morbid Mortal Wkly Rep 2015;64:1-5.

6 Smith AD, Kim YI, Refsum H. Is folic acid good for everyone? Am J Clin Nutr 2008;87:517-33.
7 Morris MC, Evans DA, Bienias JL, et al. Dietary folate and vitamin B12 intake and cognitive decline among community-dwelling older persons. Arch Neurol 2005;62:641-5.

8 Morris MS, Jacques PF, Rosenberg IH, et al. Folate and vitamin B-12 status in relation to anemia, macrocytosis, and cognitive impairment in older Americans in the age of folic acid fortification. Am J Clin Nutr 2007;85:193-200.

9 Morris MS, Jacques PF, Rosenberg $\mathrm{IH}$, et al. Circulating unmetabolized folic acid and 5-methyltetrahydrofolate in relation to anemia, macrocytosis, and cognitive test performance in American seniors. Am J Clin Nutr 2010:91:1733-44.

10 Moore E, Ames D, Mander A, et al. Among vitamin B12 deficient older people, high folate levels are associated with worse cognitive function: combined data from three cohorts. $J$ Alzheimers Dis 2014;39:661-8.

11 Wang $\mathrm{HX}$, Wahlin $\mathrm{A}$, Basun $\mathrm{H}$, et al. Vitamin $\mathrm{B} 12$ and folate in relation to the development of Alzheimer's disease. Neurology 2001;56:1188-94.

12 Obeid R, Schorr H, Eckert R, et al. Vitamin B12 status in the elderly as judged by available biochemical markers. Clin Chem 2004;50:238-41.

13 Clarke R, Sherliker P, Hin H, et al. Detection of vitamin B12 deficiency in older people by measuring vitamin B12 or the active fraction of vitamin B12, holotranscobalamin. Clin Chem 2007;53:963-70.

14 Loikas S, Koskinen P, Irjala K, et al. Vitamin B12 deficiency in the aged: a population-based study. Age Ageing 2007:36:177-83.

15 Vollset SE, Clarke R, Lewington S, et al. Effects of folic acid supplementation on overall and site-specific cancer incidence during the randomised trials: meta-analyses of data on 50000 individuals. Lancet 2013;381:1029-36.

16 Ebbing $\mathrm{M}$, Bonaa $\mathrm{KH}$, Nygard O, et al. Cancer incidence and mortality after treatment with folic acid and vitamin B12. JAMA 2009;302:2119-26.

17 Ericson UC, Ivarsson MI, Sonestedt E, et al. Increased breast cancer risk at high plasma folate concentrations among women with the MTHFR 677T allele. Am J Clin Nutr 2009;90:1380-9

18 Selhub J, Rosenberg IH. Excessive folic acid intake and relation to adverse health outcome. Biochimie [forthcoming].

19 Pfeiffer CM, Caudill SP, Gunter EW, et al. Biochemical indicators of B vitamin status in the US population after folic acid fortification: results from the National Health and Nutrition Examination Survey 1999-2000. Am J Clin Nutr 2005;82:442-50.

Cite this as: BMJ 2016;352:i734

(c) BMJ Publishing Group Ltd 2016 